\title{
Traumatic Hip Dislocation: An Experience from a Public General Hospital of Brunei
}

\author{
Pramod Devkota ${ }^{1}$, Shiraz Ahmad ${ }^{2}$
}

\begin{abstract}
Introduction: Traumatic dislocation of the hip (TDH) is an orthopedic trauma emergency, which is commonly due to high-energy trauma. Morbidity and mortality are very high usually resulting from the associated injuries sustained during the trauma. The condition of the victims worsened when associated with acetabular or femoral head fractures. The prevalence of hip dislocations is increasing worldwide.

Materials and methods: From August 2011 to March 2018, a total of 27 cases of traumatic hip dislocation were treated in a public general hospital. The emergency reduction was performed, immobilization with skin tractions was done for 3 weeks by admitting to the hospital. After 3 weeks of hospital stay, discharged and advised for non-weight bearing (NWB) crutch walk for another 3 weeks. Medical records of all patients after 1 year of dislocation were reviewed.

Results: There were $21(77.78 \%)$ males, 6 (22.22\%) females, and the mean age of the patient was of $37.59 \pm 13.69$ years (range 8-71), posterior dislocation occurred in $18(66.66 \%)$ cases, anterior dislocation on $6(22.22 \%)$ cases, and central dislocation on $3(11.11 \%)$ cases. The right hip was dislocated in 17 (62.96\%) cases and left in $10(37.04 \%)$ cases. A road traffic accident (RTA) was the cause for $16(59.25 \%)$ cases, fall injury in $8(29.62 \%)$ cases, and physical assaults in $3(11.11 \%)$ cases. Associated injuries like abdominal, thoracic, pelvic and acetabular fracture, upper and lower limbs injuries, and sacroiliac joint injury were found in $17(62.96 \%)$ cases.

Conclusion: Traumatic dislocation of the hip is a severe injury caused mostly by RTA and young adults are most commonly affected.

Keywords: Anterior, Dislocation, Hip, Posterior, Trauma.

Journal of Orthopedics and Joint Surgery (2022): 10.5005/jp-journals-10079-1052
\end{abstract}

\section{INTRODUCTION}

Traumatic dislocation of the hip (TDH) is an orthopedic emergency that is commonly due to high-energy trauma and it can cause serious permanent disability. ${ }^{1}$ Road traffic accidents (RTA) is the major cause of the TDH, and the condition is worsened when associated with the acetabular or femoral head fracture. ${ }^{2,3}$ The incidence of hip dislocation is $5.2 \%$ and it is the most common joint to dislocate in the lower extremity. ${ }^{4}$ Prompt recognition and early reduction with adequate stabilization is crucial for the successful functional outcome. ${ }^{5}$

Traumatic dislocation of the hip is classified as anterior, posterior, central, and posterior dislocation is the commonest one. ${ }^{6}$ The posterior dislocation is caused by forced adduction with internal rotation and some degree of flexion of the hip. ${ }^{7}$ The hip dislocation with or without acetabular fracture is largely dependent on the direction of the femoral head at the time of injury and the increased flexion, adduction is more likely to cause a simple dislocation with the femoral anteversion may predispose patients to simple hip dislocations. ${ }^{8}$ Generally, isolated hip dislocations are treated by closed reduction with immobilization. The delay in the reduction may result in avascular necrosis (AVN) of the femoral head, post-traumatic arthritis, and ankylosis of the hip joint. ${ }^{9}$ Irreducible dislocations, incongruent reductions, and associated fractures may require successive operative intervention. ${ }^{10}$

This study aimed to review the common causes of traumatic hip dislocation, the demography, and the pattern of dislocations with associated fractures, injuries in a public general hospital.

\section{Materials and Methods}

This is a descriptive retrospective observational study of cases hospitalized for traumatic hip dislocation at a public general hospital
${ }^{1}$ Department of Orthopaedics and Trauma Surgery, Patan Academy of Health Sciences, Patan Hospital, Lalitpur, Bagmati, Nepal

${ }^{2}$ Department of Orthopaedics, Suri Seri Begawan Hospital, Kuala Belait, Brunei Darussalam

Corresponding Author: Pramod Devkota, Department of Orthopaedics and Trauma Surgery, Patan Academy of Health Sciences, Patan Hospital, Lalitpur, Bagmati, Nepal, Phone: +977-15522278, e-mail: pramodcd@yahoo.com

How to cite this article: Devkota P, Ahmad S. Traumatic Hip Dislocation: An Experience from a Public General Hospital of Brunei. J Orth Joint Surg 2022;4(1):19-21.

Source of support: Nil

Conflict of interest: None

from August 2011 to March 2018. Computed tomography (CT) scan was not done regularly and also not required. Inclusion criteria were: (1) Patient managed at the hospital with TDH, dislocation reduced closely and surgical intervention done for acetabular fractures or other associated injuries; (2) Information available of the patient of 1 year after a dislocation. Exclusion criteria were: Dislocation of the hip due to pathological and congenital reasons, dislocation reduced by open surgical intervention, dislocation with acetabular fractures which was operated and adequate information not available on the records of the patient. Emergency reduction done and immobilization with skin tractions for 3 weeks in the hospital done. Discharged from the hospital and advised for non-weight bearing (NWB) crutch walk for another 3 weeks advised.

We analyzed the epidemiological parameters like gender, age, and nationalities for each patient. The common causes of dislocations, a pattern of dislocation and associated injuries,

(c) The Author(s). 2022 Open Access This article is distributed under the terms of the Creative Commons Attribution 4.0 International License (https://creativecommons. org/licenses/by-nc/4.0/), which permits unrestricted use, distribution, and non-commercial reproduction in any medium, provided you give appropriate credit to the original author(s) and the source, provide a link to the Creative Commons license, and indicate if changes were made. The Creative Commons Public Domain Dedication waiver (http://creativecommons.org/publicdomain/zero/1.0/) applies to the data made available in this article, unless otherwise stated. 
were reviewed. Also reviewed were the pre- and post-reduction complications of dislocations (Figs 1 and 2).

\section{Results}

A total of 27 hip dislocations were included in this time. All dislocations were reduced closely and not required open surgical reduction of the dislocation. There were 21 (77.78\%) males, 6 (22.22\%) female patients with the mean age of patient were $37.59 \pm 13.69$ years (range 8-71). The posterior dislocation was more common, and which accounted for 18 (66.66\%) cases, anterior dislocation was found in $6(22.22 \%)$ cases, and central dislocation in $3(11.11 \%)$ cases. The right hip was dislocated in 17 (62.96\%) cases and left in 10 (37.04\%) cases. An RTA was the cause for $16(59.25 \%)$ cases, fall 8 (29.62\%) cases, and physical assaults of $3(11.11 \%)$ cases. In terms of nationalities, Bruneian were the most which accounted for $42 \%$ and followed by Indonesian and Filipinos (Fig. 3). Associated injuries like abdominal, thoracic, pelvic and acetabular fracture, upper and lower limbs injuries, and sacroiliac joint injury were found in 17 (62.96\%) cases. Among them, three patients had sciatic nerve injuries. Computerized tomography (CT) scan was done on these cases with associated injuries. Based on the CT scan results, six (22.22\%) of these cases were transferred to the higher center for operative intervention. Among the three patients were operated on for acetabular fractures, two were operated on sacroiliac joint injuries and one case was operated on for openbook fractures. All these cases were followed up at our center after surgical intervention. At 1 year of follow, seven cases had hip pain and discomfort while walking. Among them, four were operated and plain radiographs reveal osteoarthritis in two cases who were operated on. MRI was done on two cases as they were very worried about the symptoms who were not operated but hip pain persisted. One patient had AVN of the femoral head on MRI. This patient was advised for core decompression but refused.

\section{Discussion}

The hip joint is an extremely stable joint which is the most difficult joint to dislocate, and traumatic hip dislocations are serious injuries. ${ }^{11}$ A force of $400 \mathrm{~N}$ (90 lbs) was required to cause dislocation of the hip joint. ${ }^{12}$ The direction of the energy vector used and the position of the lower limb at the time of injury determined the direction and type of the hip dislocation. ${ }^{13}$ In this study, the majorities of the patient were male which accounted for $77.78 \%$, and young in terms of age with the mean age being 37.59. Chigblo et al. reported the mean age of the patient was 39.6 years and males were $82.6 \% .^{14}$ Lima et al. ${ }^{1}$ reported the mean age of 34.4 years and $90 \%$ of the male suffered, which are similar to our reports. In our study, the right hip dislocated more than the left which accounted for $62.96 \%$ of cases. Sahin et al. ${ }^{15}$ reported righter hip dislocation than left but Babalola reported that more dislocation occurred on the left side. ${ }^{10}$ The main cause of the dislocation is RTA in our study and accounted for about $60 \%$. Others also reported the RTA as a major cause for dislocation and Lima et al. reported 95\%, Chigblo et al. found 86\%, and Onyemaechi and Eyichukwu reported $91 \%,{ }^{1,14,16}$ which were a higher percentage than our study. The posterior dislocation was the major type of dislocation and accounted for $66.66 \%$ of total dislocation. Others also reported the posterior dislocation as the major type of dislocation and accounted for $70-100 \%,{ }^{15,17,18}$ which was comparable with our findings. Three patients (11\%) had sciatic

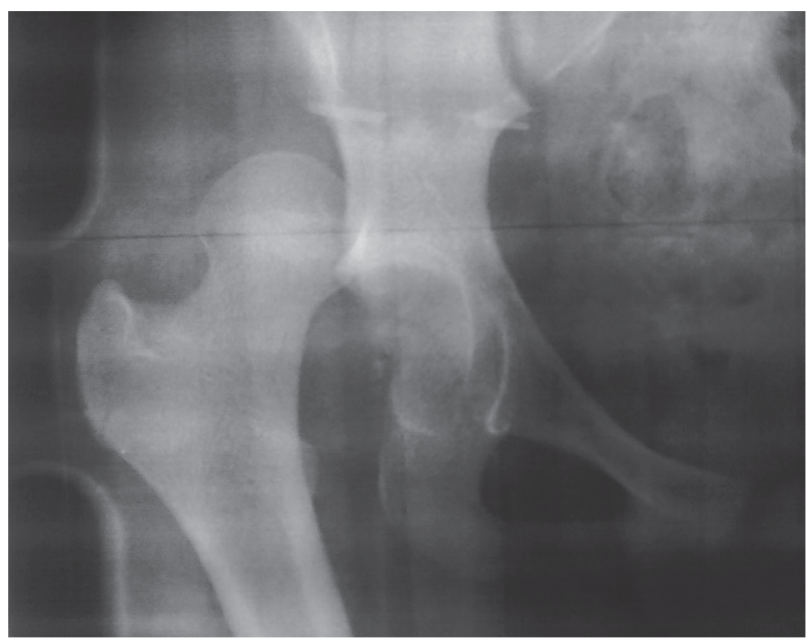

Fig. 1: Right hip dislocation on a 39-year-old man after RTA

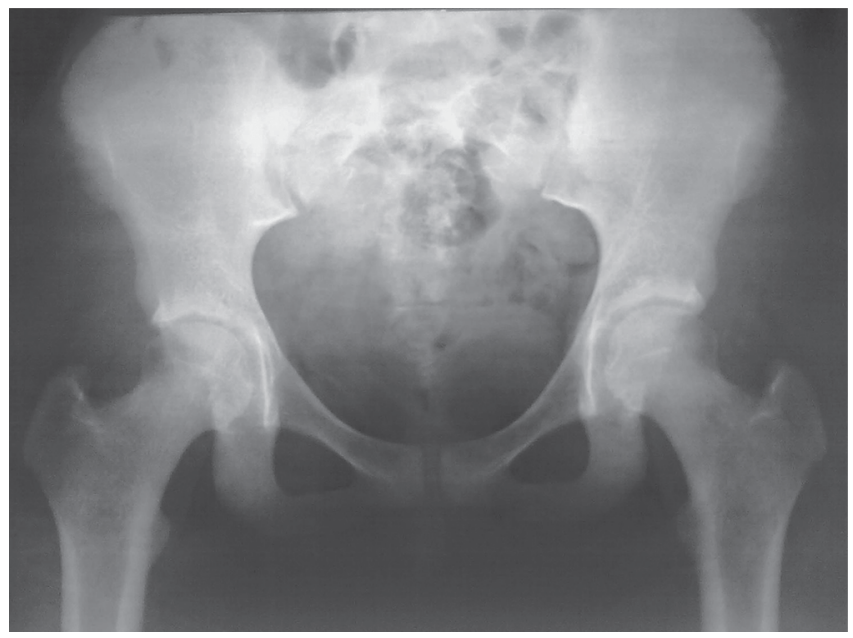

Fig. 2: After closed reduction of the dislocated hip

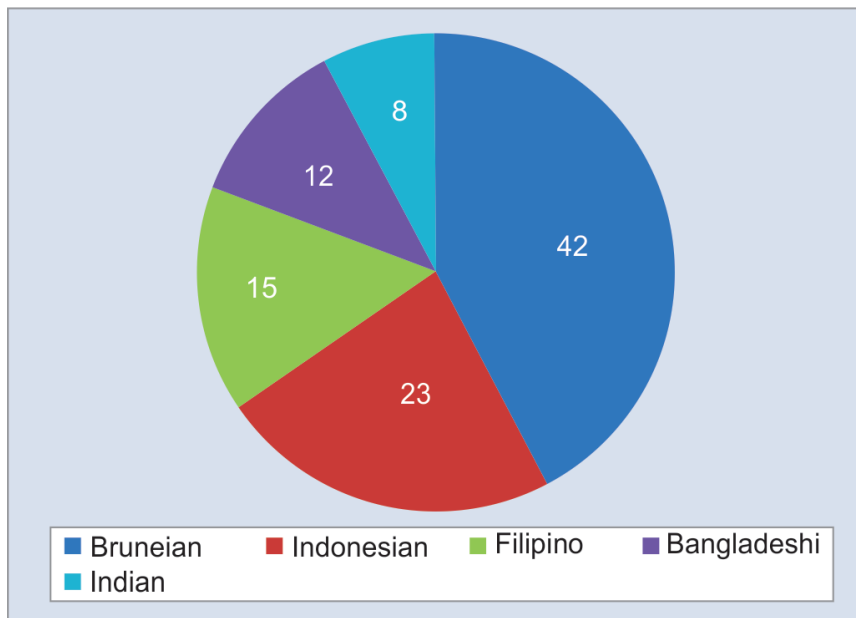

Fig. 3: Percentage of hip dislocation on different nationalities

nerve injuries in this study. Babalola et al. reported $14 \%$ of sciatic nerve injury, Hillyard and Fox reported $16 \%$ of sciatic nerve injury, and Cornwall and Radomisli reported $10 \%$ incidence of sciatic nerve injury after a traumatic hip dislocation. ${ }^{10,17,19}$ These reported incidences of sciatic nerve injuries were comparable with our study. 
In this study, associated injuries like abdominal, thoracic, pelvic and acetabular fracture, upper and lower limbs injuries, and sacroiliac joint injury were found in 17 (62.96\%) cases. Lima et al. ${ }^{1}$ reported $74 \%$ of associated injuries and Sahin et al. ${ }^{15}$ reported $71 \%$ which were slightly higher than our findings but not significant. In 1 year of follow-up, seven patients had hip pain, and two cases had osteoarthritis who was operated on. One patient got AVN of the femoral head on MRI who was not operated on for any associated injuries. The reported occurrence of AVN after dislocation of the femoral head is $1.7-40 \%$, but it could be reduced to $0-10 \%$ if the reduction is performed in the first 6 hours after trauma. ${ }^{20}$

\section{Conclusion}

Traumatic hip dislocation is an acute injury caused by high-energy trauma like an RTA. The young male patient suffered more. Posterior dislocation is the most common type and associated injuries are also very frequent.

\section{References}

1. Lima LC, do Nascimento RA, de Almeida VM,et al. Epidemiology of traumatic hip dislocation in patients treated in Ceará, Brazil. Acta Ortop Bras 2014;22(3):151-154.DOI: 10.1590/1413-78522014220300883

2. Deakin DE, Porter K. Traumatic hip dislocation in adults. Trauma 2009;11(3):189-197. DOI: 10.1177/1460408609340829

3. Sah AP, Marsh E. Traumatic simultaneous asymmetric hip dislocations and motor vehicle accidents. Orthopedics 2008;31(6):613. DOI: 10.3928/01477447-20080601-26

4. Yang NP, Chen HC, Phan DV, et al. Epidemiological survey of orthopedic joint dislocations based on nationwide insurance data in Taiwan, 2000-2005. BMC Musculoskelet Disord 2011;12(1):253. DOI: 10.1186/1471-2474-12-253

5. Olson SA, Bay BK, Pollak AN, et al. The effect of variable size posterior wall acetabular fractures on contact characteristics of the hip joint. J Orthop Trauma 1996;10(6):395-402. DOI: 10.1097/00005131-199608000-00006

6. Durakbaşa O, Okan N, Canbora K, et al. Factors affecting the results of treatment in traumatic dislocation of the hip. Acta Orthop Traumatol Turc 2005;39(2):133-141.
7. Clegg TE, Roberts CS, Greene JW, et al. Hip dislocationsepidemiology, treatment, and outcomes. Injury 2010;41(4):329-334. DOI: 10.1016/j.injury.2009.08.007

8. Upadhyay SS, Moulton A, Burwell RG. Biological factors predisposing to traumatic posterior dislocation of the hip. A selection process in the mechanism of injury. J Bone Joint Surg Br 1985;67(2):232-236. DOI: 10.1302/0301-620X.67B2.3884614

9. Amihood S. Posterior dislocation of hip. Clinical observation and review of literature. South African Medical J 1974;48(24):1029-1032.

10. Babalola R, Laiyemo E, Audu S, et al. Traumatic hip dislocations in an orthopedic center in lagos. Niger Med J 2018;59(2):20-23. DOI: 10.4103/nmj.NMJ_139_18

11. Schlickewei W, Elsässer B, Mullaji AB, et al. Hip dislocation without fracture: traction or mobilization after reduction? Injury. 1993;24(1):27-31. DOI: 10.1016/0020-1383(93)90078-k.

12. Arvidsson I. The hip joint: forces needed for distraction and appearance of the vacuum phenomenon. Scand J Rehabil Med 1990;22(3):157-161.

13. Alonso JE, Volgas DA, Giordano V, et al. A review of the treatment of hip dislocations associated with acetabular fractures. Clin Orthop Rel Res2000(377):32-43. DOI: 10.1097/00003086-200008000-00007

14. Chigblo P, Tidjani IF, Lawson E, et al. Traumatic hip dislocation in Cotonou. J Orthop 2016;13(4):268-271. DOI: 10.1016/j.jor.2016.06.006

15. Sahin V, Karakas ES, Aksu S, et al. Traumatic dislocation and fracture- dislocation of the hip: a long-term follow-up study. JTrauma 2003;54(3):520-529.DOI: 10.1097/01.TA.0000020394.32496.52

16. Onyemaechi NO, Eyichukwu GO. Traumatic hip dislocation at a regional trauma centre in Nigeria. Niger J Med 2011;20(1):124-130.

17. Hillyard RF, Fox J. Sciatic nerve injuries associated with traumatic posterior hip dislocations. Am J Emerg Med 2003;21(7):545-548. DOI: 10.1016/j.ajem.2003.08.014

18. Tornetta P, Hamid MR. Hip dislocation: current treatment regimens. J Am Acad Orthop Surg 1997;5(1):27-36. DOI: 10.5435/00124635-199701000-00004

19. Cornwall R, Radomisli TE. Nerve injury in traumatic dislocation of the hip. Clin Orthop Rel Res 2000(377):84-91. DOI: 10.1097/00003086-200008000-00012

20. Kain MS, Tornetta P. Hip dislocations and fractures of the femoral head. In Court-Brown CM, Heckman JD, McQueen MM, et al. Rockwood and Green's Fractures in Adults. 8th ed., Wolters Kluwer Health; 2015. pp. 1983-2027. 